\title{
Improvement of Corrosion Resistance and Magnetic Properties of NdFeB Sintered Magnets with $\mathrm{Cu}$ and $\mathrm{Zr} \mathrm{Co}$-Added
}

\author{
Minxiang Pan, Pengyue Zhang ${ }^{*}$, Qiong Wu, Hongliang Ge \\ Magnetism key laboratory of Zhejiang Province, China Jiliang University, Hangzhou 310018, China \\ *E-mail: zhang_pengyue@cjlu.edu.cn
}

doi: $10.20964 / 110402659$

Received: 26 January 2016 / Accepted: 22 February 2016 / Published: 1 March 2016

$\mathrm{Cu}$ and $\mathrm{Zr}$ powders are co-added as intergranular modifiers to improve the corrosion resistance of the $\mathrm{NdFeB}$ sintered magnets. Compared with the $\mathrm{Cu}$ and $\mathrm{Zr}$ free sample, the $E_{\text {corr }}$ is increased sharply from $-0.799 \mathrm{~V}$ to $-0.697 \mathrm{~V}$ for the co-added sample with $0.15 \mathrm{wt} . \% \mathrm{Cu}$ and $0.85 \mathrm{wt} . \% \mathrm{Zr}$, which demonstrate that small additions of $\mathrm{Cu}$ and $\mathrm{Zr}$ co-added can remarkably improve the electrochemical stability and corrosion resistance in salt solution. Besides, $\mathrm{Co}$ and $\mathrm{Zr}$ co-addition proved to result in relevant improvement in the magnetic properties, especially in the coercivity $H_{\mathrm{cj}}, H_{\mathrm{cj}}$ was improved from 2000 to $2181 \mathrm{kA} / \mathrm{m}$ at room temperature. Further investigation of temperature dependence of coercivity demonstrates that $\mathrm{Cu}$ and $\mathrm{Zr}$ co-addition sample shows a larger $|\beta|$ compared to that of the $\mathrm{Cu}$ and $\mathrm{Zr}$ free sample.

Keywords: Corrosion, Magnetic properties, Sintered magnet

\section{FULL TEXT}

(C) 2016 The Authors. Published by ESG (www.electrochemsci.org). This article is an open access article distributed under the terms and conditions of the Creative Commons Attribution license (http://creativecommons.org/licenses/by/4.0/). 